UDC 331.5

LBC 65.012.22

\title{
PROBLEMS OFYOUTH EMPLOYMENT IN THE COUNTRIES OF THE EURASIAN ECONOMIC UNION
}

\author{
Alena A. Petrochenko \\ Peoples' Friendship University of Russia, Moscow, Russian Federation
}

\begin{abstract}
The labor market is one of the most important spheres of the economy, one of the indicators on the basis of which we can evaluate the national prosperity, stability, and the effectiveness of social and economic transformations. In its turn, employment of the population is a necessary condition for society development and is one of the key elements influencing the living standards, staff training, material support for unemployed people. The youth is the most vulnerable category in the labor market.

The article examines the labor market of the youth of the Eurasian Economic Union (EAEU). The level of youth unemployment is analyzed, and it is revealed that its lowest level in the EAEU countries falls on Kazakhstan, and the highest - on Armenia. The main programs promoting young people in the labor market are studied. The special attention is paid to the analysis of problems of youth employment in the EAEU countries. It is revealed that the following problems exist in the EAEU countries: the increase in the share of youth in the NEET category, the non-availability of graduates of higher school, the disparity between the skills of graduates and labor market demands, the migration of young people, and the high level of youth unemployment in Armenia. Based on the results of the study, the author proposes the creation of the Youth Employment Center of the Unified Energy System of the EAEU, whose main goal will be to improve the efficiency of management in the matter of young citizens employment in the EAEU countries; granting internships to the skilled students, providing benefits to companies employing young professionals without work experience.
\end{abstract}

Key words: labor market, youth, employment, unemployment, economy, Eurasian Economic Union.

УДК 331.5

ББК 65.012 .22

\section{ПРОБЛЕМЫ ЗАНЯТОСТИ МОЛОДЕЖИ СТРАН ЕВРАЗИЙСКОГО ЭКОНОМИЧЕСКОГО СОЮЗА}

\author{
Алена Александровна Петроченко \\ Российский университет дружбы народов (RUDN University), г. Москва, Российская Федерация
}

\begin{abstract}
Аннотация. Рынок труда является одним из важнейших сфер экономики, одним из показателей, на основе которого можно делать предположение о национальном благополучии, стабильности, эффективности социально-экономических преобразований. В свою очередь, занятость населения выступает необходимым условием для общественного воспроизводства, являясь одной из основ, влияющих на уровень жизни людей, издержки общества на подбор, подготовку, переподготовку и повышение квалификации кадров, их трудоустройство, материальную поддержку людей, лишившихся работы. Наиболее уязвимой категорией на $\infty$ рынке труда является молодежь.

В статье рассмотрен рынок труда молодежи Евразийского экономического союза (ЕАЭС). Проанализирован уровень молодежной безработицы, выявлено, что самый низкий уровень по этому показателю из стран ЕАЭС наблюдается в Казахстане, а самый высокий - в Армении. Рассмотрены основные программы, способствующие становлению молодежи на рынке труда. Особое внимание в работе уделяется анализу проблем занятости молодежи в странах ЕАЭС. Выявлено, что в странах ЕАЭС имеются следующие проблемы: рост доли молодежи категории NEET, нетрудоустройство выпускников профессиональных учебных заведений, несоответствия профессионально-квалификационных навыков выпускников с запросами рынка труда, миграция молодого населения, высокая молодежная безработица в Армении. По результатам прове-
\end{abstract}


денного исследования автором предложено создание Центра занятости молодежи ЕАЭС, основная цель которого будет заключаться в повышении эффективности управления в вопросах трудоустройства граждан молодого возраста в странах ЕАЭС; предоставление успешным студентам вузов производственных стажировок, предусмотренных образовательными программами, предоставление льгот компаниям, трудоустраивающих молодых специалистов без опыта работы.

Ключевые слова: рынок труда, молодежь, занятость, безработица, экономика, Евразийский экономический союз.

\section{Введение}

В настоящее время стоит отметить возрастающее внимание к такой группе населения, как молодежь. Молодежь представляет собой социально-демографическую группу, выделяемую на основе возрастных особенностей, социального положения, места и функций в социальной структуре общества, специфических интересов и ценностей. Под термином «молодежь» понимают совокупность молодого населения, которому общество предоставляет шанс реализовать свои возможности, при этом предоставляя им льготы, но ограничивая их возможности активного участия в определенных сферах жизни социума. Стоит отметить, что в различных странах имеются свои критерии возрастных границ молодежи. Так, согласно международному определению, к молодежи относят лиц в возрасте от 15 до 24 лет, но в тех государствах, где выход молодого населения на рынок труда происходит в более позднем возрасте, к данной категории относят людей в возрасте $25-$ 29 лет [1, c. 38].

Отличительная черта данной категории населения заключается в том, что она способна наследовать, воспроизводить, а также передавать следующему поколению сложившуюся систему взаимоотношений в мире. Согласно информации $\mathrm{OOH}$, на сегодняшний день в мире проживает порядка 1,8 млрд молодого населения. В этой связи возникает необходимость в поддержании данной категории людей, так как именно они могут повлиять на многие аспекты дальнейшего будущего, а также добиться улучшения жизни в мире [6].

\section{Проблема занятости молодежи в странах ЕАЭС}

В январе 2015 г. начал действовать наиболее значимый за последние десятилетия до- кумент - Соглашение о Евразийском экономическом союзе (ЕАЭС). Данным Соглашением учреждается межгосударственное содружество, в котором гарантируется свобода движения товаров, услуг, рабочей силы и капитала, проведение общей экономической политики. Соглашение уже подписано Президентами Казахстана, Белоруссии, России, Армении и Кыргызстана [6, с. 10]. Наиболее вероятными членами для вступления в ЕАЭС в ближайшее время могут быть Республика Таджикистан, Узбекистан, а также Молдова, но вероятность вступления Молдовы невелика в связи с тем, что она принимала участие в Восточном партнерстве и подписала соглашение об ассоциации с Европейским союзом (ЕС) на Вильнюсском саммите в ноябре 2014 года [2].

Основная цель создания ЕАЭС - обеспечение условий для эффективного развития экономик стран-членов ЕАЭС в интересах роста уровня жизни населения. Особый интерес для жителей государств-членов ЕАЭС вызывают возможности по созданию общего рынка труда.

Одной из важнейших экономических и социальных проблем, которую предстоит решить ЕАЭС, является проблема молодежной занятости и безработицы. В 2016 г. в государствах ЕАЭС уровень молодежной безработицы (лица от 15 до 24 лет) составлял 18,6 \%, при том, что уровень общей безработицы находился на уровне $8 \%$ (см. рис. 1, табл. 1).

Согласно прогнозам, в России к 2020 г. количество занятого населения будет составлять 73,1 млн человек, при этом глобальный уровень безработицы среди молодежи, как ожидается, в 2018 г. будет составлять 13,1 \% [4]. В Казахстане прогнозируемый уровень молодежной безработицы будет равен 3,9 \% [12]. Особенно актуальна проблема безработицы сегодня среди молодежи в Армении. По данным доклада Международной 
A.А. Петроченко. Проблемы занятости молодежи стран Евразийского экономического союза

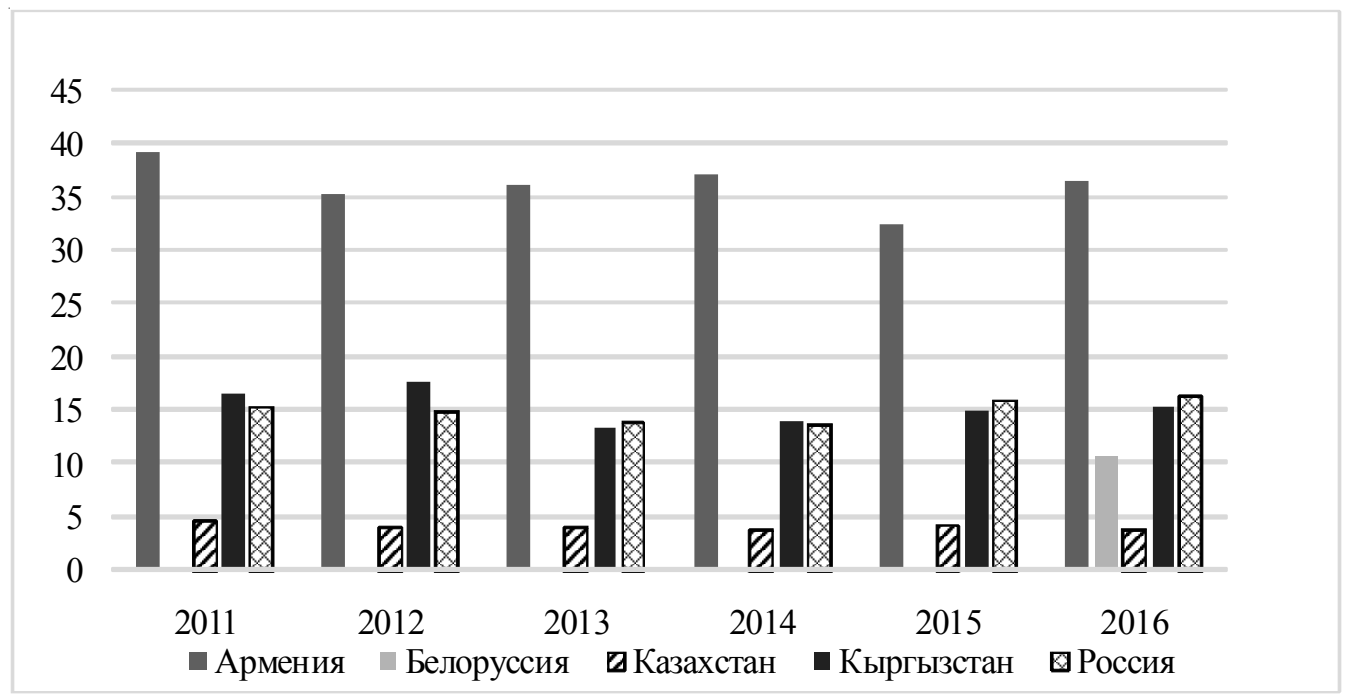

Рис. 1. Уровень молодежной безработицы в ЕАЭС (\%)

Примечание. Составлено автором по: [11, с. 14].

Молодежь ЕАЭС в возрасте от 15 до 24 лет, которая не учится, не работает

и не приобретает профессиональных навыков (по данным выборочного обследования рабочей силы; тыс. человек)

\begin{tabular}{|l|c|c|c|c|c|}
\hline \multicolumn{7}{|c|}{2012 г. } & 2013 г. & 2014 г. & 2015 г. & 2016 г. \\
\hline Всего & 2306 & 2274 & 2166 & 2067 & 2001 \\
\hline $\begin{array}{c}\text { В том числе } \\
\text { Мужчины }\end{array}$ & 951 & 911 & 872 & 846 & 851 \\
\hline Женщины & 1355 & 1363 & 1294 & 1221 & 1150 \\
\hline \multicolumn{6}{|c|}{ \% от численности молодежи соответствующего пола и возрастной группы } \\
\hline Мужчины & 9,7 & 9,3 & 9,5 & 9,6 & 10,3 \\
\hline Женщины & 14,4 & 14,4 & 14,7 & 14,5 & 14,6 \\
\hline
\end{tabular}

Примечание. Составлено автором по: [9].

организации труда, уровень безработицы среди молодежи в Армении достигает более $40 \%$. Наиболее серьезно проблема обстоит в сельской местности, поскольку за последние годы сильно увеличилась миграция из сел в города и за границу [14].

Возросла доля молодежи категории NEET (не получающие профессиональную подготовку или образование, нигде не работающие молодые люди) [3]. Так, например, в 2015 г. данный показатель составлял $12 \%$, а в 2016 г. произошло увеличение на 0,4 \%, причем выше данный показатель наблюдался у девушек [9].

Как показывает практика последних лет, основную массу мигрантов составляет молодое население [5]. Это связано с невозмож- ностью молодежи в достаточной степени реализовать себя на родине, в частности, найти достойную оплату труда. При этом прослеживается следующая закономерность: чем выше уровень образования, тем более выражено у молодежи желание покинуть страну. Таким образом, можно утверждать, что из страны мигрирует в первую очередь высокообразованная молодежь.

Нужно отметить, что существует актуальная проблема сложности в трудоустройстве выпускников профессиональных учебных заведений. Среди наиболее часто встречающихся причин затруднения в трудоустройстве выпускников можно выделить: отсутствие спроса на профессию, отсутствие стажа (опыта) работы, недостаточный уровень оплаты 
труда, отсутствие вакансий. При трудоустройстве молодежь сталкивается с проблемой несоответствия профессионально-квалификационных навыков выпускников с запросами рынка труда. Это происходит из-за дисбаланса процессов подготовки специалистов и текущих потребностей рынка труда. В связи с трудностями при трудоустройстве молодые люди могут утратить навыки, полученные во время обучения в средних или высших учебных заведениях, профессионально не развиваться, а также утратить возможность карьерного роста [7].

Среди основных причин высокого числа безработных в странах ЕАЭС прежде всего необходимо отметить неблагоприятные условия для развития среднего и малого бизнеса, а также монополизированность рынка. Кроме того, средств из бюджета, выделяемых на программы по трудоустройству молодежи, сегодня явно недостаточно. Например, в Армении реализуемые государственные программы не в полной мере справляются с ростом числа безработных. Вместе с тем, согласно прогнозам экспертов Международной организации труда, если не будут предприняты радикальные действия, в ближайшее время уровень безработицы в Армении будет стремительно расти, и в 2018 г. к числу безработных можно будет отнести каждого пятого жителя страны [14].

Как показывает практика, в 2016 г. на рынке труда ЕАЭС было заявлено 1245,4 тыс. свободных рабочих мест (табл. 2), в основном это трудовые места в сфере услуг, торговли, госсекторе (врачи, учителя, сотрудники государственных органов, рабочие профессии). Но главная проблема заключается в том, что средняя заработная плата в этих облас- тях ниже, чем в других, что, безусловно, демотивирует молодежь, чьи ожидания были гораздо выше.

Наибольший процент занятого населения по видам экономической деятельности ЕАЭС трудится в сфере услуг, затем в России и Белоруссии следует промышленность, в Армении, Казахстане и Кыргызстане - сферы сельского, лесного и рыбного хозяйства $[8$, с. 81]. При этом в России в последние годы наибольшее количество молодых людей было трудоустроено в таких отраслях, как финансовая деятельность, гостиницы и рестораны, оптовая и розничная торговля. В Республике Казахстан больше всего молодежи работает в оптовой и розничной торговле, сельском, лесном и рыбном хозяйстве, образовании. Предполагается, что в будущем увеличится спрос на молодых сотрудников таких специальностей, как инженеры, IT-специалисты, бизнесконсультанты, программисты, а также специалисты в области нанотехнологий.

Стоит отметить, что вопросами молодежи в Казахстане и России занимаются отдельные ведомства (в Казахстане - Департамент молодежной политики Министерства образования и науки РК, в России - Федеральное агентство по делам молодежи). В остальных странах-участницах Союза подобные ведомства входят в другую структуру (см. табл. 3).

Проанализировав ситуацию на рынке труда молодежи, нужно отметить, что в тех странах ЕАЭС, где создано отдельное ведомство, занимающееся молодежной политикой в стране, рассматриваются экономические показатели по рынку труда молодежи, что гораздо упрощает процедуру оценки текущей ситуации, а также разработки рекомендаций по усовершенствованию молодеж-

Таблича 2

Число свободных рабочих мест, заявленных

в государственные службы занятости населения (на конец года, тыс. мест)

\begin{tabular}{|l|r|r|r|r|r|}
\hline \multicolumn{1}{|c|}{ Страна } & 2012 г. & 2013 г. & 2014 г. & 2015 г. & 2016 г. \\
\hline Армения & 1,7 & 1,5 & 1,7 & 1,8 & 1,3 \\
\hline Белоруссия & 62,0 & 50,5 & 33,6 & 28,7 & 36,0 \\
\hline Казахстан & 10,3 & 9,4 & 11,1 & 16,3 & 26,0 \\
\hline Кыргызстан & 7,1 & 6,9 & 6,5 & 6,2 & 6,5 \\
\hline Россия & 1298,3 & 1377,5 & 1397,4 & 1135,2 & 1175,6 \\
\hline ЕАЭС & 1379,4 & 1445,8 & 1450,3 & 1188,2 & 1245,4 \\
\hline
\end{tabular}

Примечание. Составлено автором по: [8, с. 85]. 
А.А. Петроченко. Проблемы занятости молодежи стран Евразийского экономического союза

Таблица 3

Ведомства, отвечающие за молодежную политику в странах ЕАЭС

\begin{tabular}{|l|l|l|}
\hline $\begin{array}{c}\text { Страна-член } \\
\text { ЕАЭС }\end{array}$ & \multicolumn{1}{|c|}{$\begin{array}{c}\text { Отдельное ведомство } \\
\text { по делам молодежи }\end{array}$} & \multicolumn{1}{|c|}{$\begin{array}{c}\text { Ведомство, } \\
\text { входящее в другую структуру }\end{array}$} \\
\hline Россия & $\begin{array}{l}\text { Федеральное агентство } \\
\text { по делам молодежи }\end{array}$ & \multicolumn{1}{|c|}{-} \\
\hline Белоруссия & - & $\begin{array}{l}\text { Министерство образования } \\
\text { Республики Белоруссия }\end{array}$ \\
\hline Армения & - & $\begin{array}{l}\text { Министерство по делам спорта } \\
\text { и молодежи }\end{array}$ \\
\hline Казахстан & $\begin{array}{l}\text { Департамент молодежной } \\
\text { политики Министерства } \\
\text { образования и науки РК }\end{array}$ & $\begin{array}{l}\text { Министерство образования } \\
\text { и науки Киргизской Республики }\end{array}$ \\
\hline Кыргызстан & \multicolumn{2}{|c}{} \\
\hline
\end{tabular}

Примечание. Составлено автором по: [13].

ного рынка труда, в то время как в странах, где данное ведомство отсутствует, данные по рынку труда молодежи предоставляются лишь частично.

\section{Практические аспекты управления молодежной занятостью в ЕАЭС}

Безусловно, перечисленные проблемы актуальны не во все странах ЕАЭС, при этом опыт некоторых из стран-участниц может быть полезен для остальных государств. Так, например, наиболее благоприятная ситуация сегодня сложилась на рынке труда молодежи Казахстана, где уровень молодежной безработицы является наименьшим среди остальных стран Союза и на 2016 г. составлял всего $3,8 \%$ [11, с. 14]. Благодаря проводимой государственной политике в отношении молодежи, в том числе молодежной занятости, которая формируется посредством региональных, отраслевых и государственных программ, удается оптимизировать ситуацию на рынке труда. В Казахстане каждый год проводятся конгрессы молодежи, конференции (как внутригосударственные, так и международные), молодежные форумы, слеты активистов студенческой молодежи, патриотические собрания, круглые столы и мастер-классы. В стране популярна программа «Молодежная биржа труда», основная цель которой заключается в предоставлении вакансий для молодых, программа «С дипломом в село», которая способствует трудоустройству молодежи в сельской местности и пр. Представленный опыт можно применять и во всех остальных стра- нах Союза с целью улучшить положение молодежи на рынке труда.

Необходимо в странах ЕАЭС внедрять программы, которые будут способствовать снижению несоответствия между навыками выпускников вузов и требованиями к квалификации, необходимыми при трудоустройстве, благодаря которым работодатели будут охотнее принимать выпускников. Так, например, в Белоруссии применяется программа «Семена будущего», в соответствии с которой белорусские студенты могут поехать на двухнедельное обучение в Китай, где для них предоставлена возможность воспользоваться современным китайским опытом развития ИТ-технологий [2]. Представленный проект позволяет внести свой вклад в развитие высоких технологий, а также призван привлечь белорусскую молодежь к изучению новых технологий. В Армении в 2016 г. молодое население принимало участие в государственной программе занятости «Организация трудовой практики безработных, имеющих профессию, но не имеющих трудового стажа». Подобные меры поддержки молодого населения имеют положительный резонанс, так как способствуют приобретению ключевых профессиональных навыков, на что работодатели обращают внимание при рассмотрении кандидата на соответствующую должность.

В последнее время наибольшую популярность приобрела система коммуникативных площадок, цель которых заключается в обобщении опыта и формировании навыков и компетенций у молодого населения, - так называемая система молодежных форумов. Мо- 
лодому поколению, специализирующемуся по различным направлениям, предоставляется возможность получения грантов. Интересная молодежная площадка на базе УРГЭУ в Екатеринбурге - это Евразийский экономический форум молодежи (ЕЭФМ), где ежегодно проходит конкурс на лучший проект. В данном мероприятии молодежь Кыргызстана все чаще занимает призовые места. Наиболее популярен проект Молодежный экономический клуб фонда «Евразийцы - новая волна». Представлено огромное количество молодежных площадок в сети Интернет, которые, конечно, объединяют евразийскую молодежь и не только, по различным сферам интересов. Существует популярный проект на пространстве СНГ «Бизнес-молодость» и много других подобных, где молодому населению предоставляют бесплатные консультации, а также оказывают помощь в квалифицированном написании стартапа, или бизнес-плана. Действует молодежно-общественное движения «Молодая Евразия», которое представляет собой общеевразийское молодежное общественное движение, выступающее за создание Евразийского союза на принципах возрожденного евразийства. Международное молодежное движение «Евразийский экономический форум молодежи» (ЕЭФМ) представляет собой объединение интеллектуальной молодежи разных стран, а также является стартовой площадкой для карьерного и личностного роста молодежи в науке, проектной деятельности и предпринимательстве, способствует реализации творческого потенциала. Важнейшими преимуществами для молодежи от реализации такого рода площадок является то, что молодой человек может получить практический опыт, а также зарекомендовать себя как высококлассный специалист по полученной профессии, что в дальнейшем может оказать помощь при трудоустройстве молодого специалиста.

\section{Меры совершенствования молодежного рынка труда в странах ЕАЭС}

Проанализировав рынок труда молодежи, мы предлагаем сформировать отдельный Центр занятости молодежи ЕАЭС. Это необ- ходимо для того, чтобы осуществлять расчет по ряду показателей, к примеру: численность молодого населения трудоспособного возраста, процент молодежи трудоспособного возраста от общей численности населения страны, уровень безработицы среди молодежи, процент бюджетных расходов на молодежную политику и пр., - что позволит проводить наиболее детальный анализ состояния рынка труда молодежи.

Центр занятости молодежи будет представлять собой помещение (зал, комната, кабинет), оснащенное средствами коммуникаций (видеоконференцсвязь, конференц-связь и другие средства интерактивного предоставления информации). Центр занятости будет представлен в каждой стране ЕАЭС, и вся эта система будет функционировать как единый информационный орган. Цель данного Центра будет заключаться в повышении эффективности управления в вопросах трудоустройства граждан в странах ЕАЭС. Центр занятости молодежи ЕАЭС - это интегрированная информационная среда, обеспечивающая взаимодействие определенных ведомств и предназначенная для оперативного решения вопросов в сфере занятости населения стран ЕАЭС.

Основные задачи Центра занятости молодежи ЕАЭС:

1) взаимодействие в режиме онлайн ведомств, отвечающих за молодежную политику в странах ЕАЭС;

2) регулярный сбор данных из стран ЕАЭС о текущем состоянии рынка труда молодежи, в том числе анализ полученной информации;

3) прогнозирование наиболее востребованных специальностей на рынке труда молодежи в ЕАЭС;

4) обеспечение взаимодействия посредством современных технологий Центра с ЕЭК (Евразийской экономической комиссией), государственными органами, университетами, организациями;

5) оказание содействия в трудоустройстве молодежи в рамках ЕАЭС.

Деятельность данной структуры будет отображаться на сайте Центра, где каждый человек сможет ознакомиться с интересующей информацией, касающейся занятости населения 
в ЕАЭС. Вследствие функционирования Центра занятости ЕАЭС возможны: оптимизация взаимодействия между потенциальными сотрудниками и организациями, нуждающимися в квалифицированном персонале в рамках ЕАЭС; эффективный обмен специалистами между странами Союза; проведение единой политики в области занятости молодежи.

Предлагается реформировать системы высшего и среднеспециального образования. Так, для повышения личного потенциала молодежи образовательные программы должны предусматривать возможность прохождения успевающими студентами производственных стажировок, которые дают бесценный опыт для будущего трудоустройства. Например, для студентов технических вузов необходима поддержка государства в виде организации студенческих трудовых отрядов для работы на строительстве крупных объектов в ЕАЭС.

Кроме того, необходимо разработать систему стимулирования работодателей, которые принимают молодежь, не имеющую опыта работы. Принимая молодого специалиста в компанию, работодатель может прикрепить его к квалифицированному специалисту (наставнику), который обучит его основным навыкам непосредственно во время рабочего процесса. Впоследствии опытный сотрудник, занимающийся с новичком, может быть награжден руководством компании, в то время как для самой компании будут предоставлены особые льготы, так как она способствует снижению уровня безработных среди молодого населения.

\section{Заключение}

Молодежь является движущей силой экономического развития любого государства. Неиспользование данного ресурса может оказать отрицательное влияние на экономику, а также способно нарушить социальную стабильность не только отдельного региона, но и страны в целом. Изучив основные проблемы, с которыми молодежь, выходящая на рынок труда, сталкивается на всей территории ЕАЭС, необходимо делать упор на системные мероприятия, сочетающие политику как в сфере образования, так и в профессиональном обучении с целенаправленными мерами в области занятости молодежи.
На сегодняшний день функционирует много молодежных структур, осуществляющих разнообразную деятельность как на территории России, так и на пространстве ЕАЭС, а также сотрудничающих с молодежными организациями по всему миру. Спектр мероприятий данных организаций весьма широк, начиная от семинаров и конференций и заканчивая форсайт-сессиями и выездными лагерями. Большинство таких мероприятий проводятся для сплочения и вовлечения в определенную молодежную среду. В настоящее время государственные структуры проводят большую работу по объединению молодежных ресурсов в политику льготного трудоустройства, хотя пока уделяется не так много внимания формированию среды для реализации собственных проектов и идей молодежи [7].

Содействие молодежной занятости выступает одной из важнейших задач любого государства, в частности служб занятости, отвечающих за преодоление рассогласованности между существующей системой профессионального образования и потребностями рынка труда в молодых специалистах, характеризующимися постоянным повышением требований работодателей к соискателям рабочих мест. В этой связи актуально открытие Центра занятости молодежи ЕАЭС, который обеспечит эффективное взаимодействие ведомств, отвечающих за молодежную политику в странах ЕАЭС, а также позволит решить вопросы, связанные с занятостью молодежи, в более короткие сроки.

\section{СПИСОК ЛИТЕРАТУРЫ}

1. Анализ рынка труда молодежи : Пакет учебно-информационных материалов по рынку труда молодежи / группа технической поддержки по вопросам достойного труда и Бюро МОТ для стран Восточной Европы и Центральной Азии, Employment Policy Department. - M. : MOT, 2015. $147 \mathrm{c}$.

2. Анатолий Калинин принял участие в церемонии подписания трехстороннего меморандума о сотрудничестве в области организации обучающего проекта «Семена будущего». - Электрон. дан. Режим доступа: http:// http://www.government.by/ru/ content/6691 (дата обращения: 31.03.2017).

3. Варшвавская, Е. Я. Молодежь, исключенная из сферы занятости и образования, в странах 
ЕС и России / Е. Я. Варшвавская // Вопросы статистики. - 2015. - № 4. - С. 40-47.

4. Доклад о положении молодежи и реализации государственной молодежной политики в Российской Федерации «Молодежь и молодежная политика в России в контексте глобальных тенденций» / Министерство образования и науки Российской Федерации. - Федеральное агентство по делам молодежи, 2015. - 149 с.

5. Дуйсенбекова, А. Пути преодоления проблем молодежной занятости / А. Дуйсенбекова // G-Global : официальный сайт инфо-коммуникативной площадки. - Электрон. дан. - Режим доступа: http:/group-global.org/kk/node/42663(дата обращения: 20.10.2017).

6. Евразийская экономическая интеграция 2017 / Центр интеграционных исследований. - СПб., 2017. - 89 c.

7. Евразийский банк развития. - Электрон. дан. - Режим доступа: https:/eabr.org/analytics/ integration-research/cii-reports/integratsionnyybarometr-eabr-2016/(дата обращения: 20.10.2017).

8. Евразийский экономический союз в цифpax : статистический ежегодник / Евразийская экономическая комиссия. - М., 2016.

9. Жихарева, О. Б. Влияние Резолюции о статистике трудовой деятельности, занятости и недоиспользования рабочей силы, принятой 19-ой МКСТ, на систему показателей достижения Целей устойчивого развития, Международный семинар «Цели устойчивого развития: взгляд в будущее. Интеграционное сотрудничество в социально-демографической статистике ЕАЭС», 23 нояб. 2017 г., г. Москва : [презентация] / О. Б. Жихарева. - Электрон. дан. Режим доступа: http://www.eurasiancommission.org/ ru/act/integr_i_makroec/dep_stat/events/SDG\% 20stat_seminar/Documents/Росстат_Жихарева \%20ЦУР_23\%20ноября.pdf (дата обращения: 31.03.2017). - Загл. с экрана.

10. Кофнер, Ю. Пути дальнейшего развития ЕАЭС: расширение или модернизация? // Центр Евразийских исследований [сайт]. - Электрон. дан. Режим доступа: http://eurasian-studies.org/archives/ 487 (дата обращения: 20.10.2017). - Загл. с экрана.

11. О рынке труда в Евразийском экономическом союзе : Аналитический обзор 30 октября 2017 г. / Евразийская экономическая комиссия. - М., 2017. $18 \mathrm{c}$.

12. Прогноз - молодежная безработица. Электрон. дан. - Режим доступа: http://ru. tradingeconomics.com/forecast/youth-unemploymentrate (дата обращения: 31.03.2017). - Загл. с экрана.

13. Росмолодежь. Информационно-справочные материалы. - Электрон. дан. - Режим доступа: https://fadm.gov.ru/ (дата обращения: 20.10.2017). Загл. с экрана.
14. Стамболцян, Г. Армения - единоличный лидер постсоветского пространства по уровню безработицы / Г. Стамболцян. - Электрон. дан. -22 янв. 2014 г. - Режим доступа: https://rus.azatutyun.am/a/ 25238502.html (дата обращения: 20.10.2017). - Загл. с экрана.

\section{REFERENCES}

1. Analiz rynka truda molodezhi: Paket uchebno-informatsionnykh materialov po rynku truda molodezhi [The Analysis of Youth Labor Market]. Moscow, MOT Publ., 2015. 147 p.

2. Anatoliy Kalinin prinyal uchastie $v$ tseremonii podpisaniya trekhstoronnego memoranduma o sotrudnichestve voblasti organizatsii obuchayushchego proekta «Semena budushchego» [Anatoly Kalinin Took Part in the Ceremony of Signing a Tripartite Memorandum on Cooperation in the Sphere of Organizing the Training Project "Seeds of the Future"]. URL: http://www.government.by/ru/content/6691. (accessed October 20, 2017).

3. Varshvavskaya E.Ya. Molodezh, isklyuchennaya iz sfery zanyatosti i obrazovaniya, v stranakh ES i Rossii [Young People Excluded from Employment and Education in the EU and Russia]. Voprosy statistiki, 2015, no. 4, pp. 40-47.

4. Doklad o polozhenii molodezhi i realizatsii gosudarstvennoy molodezhnoy politiki v Rossiyskoy Federatsii «Molodezh $i$ molodezhnaya politika $v$ Rossii v kontekste globalnykh tendentsiy» [Report on Youth and Implementation of the State Youth Policy in the Russian Federation "Youth and Youth Policy in Russia in the Context of Global Trends"]. Ministerstvo obrazovaniya i nauki Rossiiskoy Federatsii. Federalnoe agentstvo po delam molodezhi [Ministry of Education and Science of the Russian Federation. Federal Agency for Youth Issues], 2015. 149 p.

5. Duysenbekova A. Puti preodoleniya problem molodezhnoy zanyatosti [The Ways to Overcome the Problems ofYouth Employment]. G-Global: ofitsialnyy sayt info-kommunikativnoy ploshchadki [G-Global: official website of the info-communication platform]. URL: http://group-global.org/kk/node/42663. (accessed October 20, 2017).

6. Evraziyskaya ekonomicheskaya integratsiya 2017 [The Eurasian Economic Integration 2017]. Tsentr integratsionnykh issledovaniy [The Centre for Integration Research]. Saint Petersburg, 2017. 89 p.

7. Evraziyskiy bank razvitiya [The Eurasian Bank of Development]. URL: https://eabr.org/analytics/ integration-research/cii-reports/integratsionnyybarometr-eabr-2016/. (accessed October 20, 2017).

8. Evraziyskiy ekonomicheskiy soyuz v tsifrakh: statisticheskiy ezhegodnik [The Eurasian 
Economic Union in Figures: Statistics Yearbook]. Evraziyskaya ekonomicheskaya komissiya [Eurasian Economic Commission]. Moscow, 2016. 23 p.

9. Zhikhareva O.B. Vliyanie Rezolyutsii o statistike trudovoy deyatelnosti, zanyatosti $i$ nedoispolzovaniya rabochey sily, prinyatoy 19-oy MKST, na sistemu pokazateley dostizheniya Tseley ustoychivogo razvitiya, Mezhdunarodnyy seminar «Tseli ustoychivogo razvitiya: vzglyad v budushchee. Integratsionnoe sotrudnichestvo $v$ sotsialnodemograficheskoy statistike EAES», 23 noyab. 2017 g., g. Moskva: prezentatsiya [The Impact of the Resolution on Labor Force Statistics, Employment and Underutilization of the Workforce Adopted by the 19th MKST, on the System of Indicators for the Achievement of the Goals of Sustainable Development. International Seminar "Goals of Sustainable Development: Ideas for the Future. Integrational Cooperation in the Socio-Demographic Statistics EAES (Moscow, November 23, 2017): Presentation]. URL: http:// www.eurasiancommission.org/ru/act/ integr_i_makroec/dep_stat/events/SDG\%20stat seminar/Documents/Росстат_Жихарева\%20ЦУР 23\%20ноября.pdf. (accessed October 20, 2017).
10. Kofner Yu. Puti dalneyshego razvitiya EAES: rasshirenie ili modernizatsiya? [Ways of Further Development of theEAEC: Expansion or Modernization?] Tsentr integratsionnykh issledovaniy [The Centre for Integration Research]. URL: http://eurasian-studies.org/ archives/487. (accessed October 20, 2017).

11. Orynke truda v Evraziyskom ekonomicheskom soyuze: Analiticheskiy obzor 30 oktyabrya $2017 \mathrm{~g}$. [On the Labor Market in the Eurasian Economic Union. Analytic Review of October 30, 2017]. Evraziyskaya ekonomicheskaya komissiya [Eurasian Economic Commission], Moscow, 2017. 18 p.

12. Prognoz - molodezhnaya bezrabotitsa [Forecast - Youth Unemployment]. URL: http://ru. tradingeconomics.com/forecast/youth-unemploymentrate. (accessed October 20, 2017).

13. Rosmolodezh. Informatsionno-spravochnye materialy [Russian Youth. Reference Materials]. URL: https://fadm.gov.ru/. (accessed October 20, 2017).

14. Stamboltsyan G. Armeniya-edinolichnyy lider postsovetskogo prostranstva po urovnyu bezrabotitsy [Armenia Is the Sole Leader of the Post-Soviet Space in Terms of Unemployment]. URL: https://rus.azatutyun.am/ a/25238502.html (accessed October 20, 2017).

\section{Information about the Author}

Alena A. Petrochenko, Assistant, Department of Management, Faculty of Economics, Peoples' Friendship University of Russia, Miklukho-Maklaya St., 6, 117198 Moscow, Russian Federation, petrochenko_aa@rudn.university.

\section{Информация об авторе}

Алена Александровна Петроченко, ассистент кафедры менеджмента, Российский университет дружбы народов (RUDN University), ул. Миклухо-Маклая, 6, 117198 г. Москва, Российская Федерация, petrochenko_aa@rudn.university. 